\title{
Analysis of drug promotional literatures in a tertiary care hospital: a cross sectional study
}

\author{
Noopur Vyas*, Savita Shahani
}

Department of Pharmacology, MGM Medical College, Navi Mumbai, Maharashtra, India

Received: 12 March 2019

Revised: 26 March 2019

Accepted: 03 April 2019

*Correspondence to:

Dr. Noopur Vyas,

Email: noopur1192@gmail.com

Copyright: (C) the author(s), publisher and licensee Medip Academy. This is an openaccess article distributed under the terms of the Creative Commons Attribution NonCommercial License, which permits unrestricted noncommercial use, distribution, and reproduction in any medium, provided the original work is properly cited.

\begin{abstract}
Background: Large numbers of new drugs are introduced into the market every day and pharmaceutical companies are in the business of development and selling of new drug. There are different modes of drug promotion which include visual aids, leave behind leaflets and audio visuals. Drug Promotional Literatures (DPL's) claim to provide vital and accurate information regarding the drug. To ensure rational use of drugs a set of standards laid by the WHO for ethical drug promotion.

Methods: A cross sectional observational study was performed in Department of Pharmacology at a tertiary care teaching hospital of Navi Mumbai. A total of 100 drug promotional literatures were randomly collected from different outpatient departments and were evaluated by using WHO guidelines.

Results: None of drug promotional literature fulfilled all WHO criteria. Generic name, Brand name, active ingredients were mentioned in all. The problem causing ingredient was not mentioned in any of the cases. Safety information was not complete, adverse drug reactions were mentioned in only $45 \%$ of the cases, contraindications and drug interactions were mentioned in $39 \%$ of the cases. Manufacturer details including name and address of manufacturer was mentioned in $67 \%$ of the DPL's. References were mentioned in $80 \%$ of the literature out of which $84 \%$ were from journal articles.

Conclusions: None of the DPL's satisfied all the WHO criteria. Incomplete information may lead to irrational prescription of drugs. Therefore, more strict regulations need to be implemented and physicians must critically evaluate DPL's before considering the same for prescribing.
\end{abstract}

Keywords: Drug promotion literatures, Ethical drug promotions, Rational drug prescribing, WHO guidelines

\section{INTRODUCTION}

Large numbers of new drugs are introduced into the market every day. Pharmaceutical companies are in the business of development and selling of new drugs. These are accepted in health care system through physicians, and its availability is of little value unless the physician is aware of its existence and has scientific information to use it effectively. ${ }^{1}$ Drug manufactures or distributors are focused on promoting the new drugs to the target audience which in this case are the health care professionals. ${ }^{2}$ According to the "ethical criteria for medicinal drug promotion" by WHO, "drug promotion" refers to all informational and persuasive activities by manufacturers and distributors of the pharmaceutical industry, the effect of which is to induce a favourable prescription, supply, purchase, and/or use of medicinal drug. ${ }^{3}$ Different modes of drug promotion are used by the pharmaceutical companies which include visual aids , drug reminders and audio visuals. ${ }^{1}$ Drug Promotional Literatures (DPL's) claim to provide vital and accurate information regarding the drug that is being promoted to the physician. Many times, it is the only 
source of information on which treating physicians depend on for updating their knowledge about existing and novel drugs. ${ }^{4}$ Medicinal promotion has a huge impact on the physicians' prescribing pattern. Although pharmaceutical industries have the right to promote their products it should be done ethically. The promotions should be informative, reliable, truthful and up to date. However, to make the promotion effective pharmaceutical industries do not adhere to ethical principles which can lead to irrational use of drugs. ${ }^{1}$ Hence, there are a set of standards laid by the WHO, "International federation of pharmaceutical manufacturers and associations (IFPMA) and the Organization of pharmaceutical producers of India (OPPI), where the objective is to support and encourage the improvement in healthcare through the rational use of drugs. ${ }^{5}$ Many studies have illustrated that information disseminated through DPLs is inconsistent with the code of ethics. ${ }^{6}$ However, not enough studies have been conducted in the Indian setup to gauge this issue and with this viewpoint the present study was taken up to critically review the DPL's and to evaluate the collected DPL's for accuracy, consistency, and validity of the information presented in it, using World Health Organization (WHO) criteria for ethical medicinal drug promotion.

\section{METHODS}

It was an observational, cross-sectional study conducted at the outpatient departments (OPD's) of MGM Medical College, Navi Mumbai, a tertiary care teaching hospital in India for period of 3 months from October 2018 to December 2018. OPDs of various clinical departments were visited and printed DPL's from these OPD's were collected. Medical devices, equipment, orthopedic prosthesis, ayurvedic medicines, reminder advertisements, drug name lists and literatures promoting more than 4 brands were excluded. Only DPL's of allopathic drugs were collected. All DPLs were evaluated by WHO criteria for fulfilment of each of the following parameters (WHO 1988): $:^{7}$

- $\quad$ The name(s) of the active ingredient(s) using either international non-proprietary names (INN) or the approved generic name of the drug

- The brand names

- Content of active ingredient(s) per dosage form or regimen

- Name of other ingredients known to cause problems;

- Approved therapeutic uses

- Dosage form or regimen

- $\quad$ Side-effects and major adverse drug reactions

- Precautions, contra-indications, and warnings

- Major interactions

- Name and address of manufacturer or distributor

- Reference to scientific literature as appropriate

All DPL's were assessed for fulfilment of all the criterion mentioned above. References were also analysed as their type, source and authenticity. The data was added in
Microsoft Office Excel software (version 2017) and analysed using descriptive analysis.

\section{RESULTS}

A total of 100 Drug promotional literatures were screened and were evaluated for its concurrence with WHO guidelines. Out of 100 drugs, 52\% were single drug formulation and $48 \%$ fixed dose combinations (FDCs) (Figure 1).

Out of all the drug promotional literatures evaluated none of the drug promotional literatures fulfilled all WHO criteria. Generic name, Brand name and active ingredient were mentioned in $100 \%$ of the Drug promotional literatures. However, the problem causing ingredient was not mentioned in any of the cases. Approved use and dosage form were mentioned in $100 \%$ of the cases. Safety information was provided in many DPL's out of which adverse drug reactions were mentioned in $45 \%$ of the cases, contraindications and drug interactions were mentioned in $39 \%$ of the cases. Manufacturer details including name and address of manufacturer was mentioned in $67 \%$ of the DPL's (Table 1).

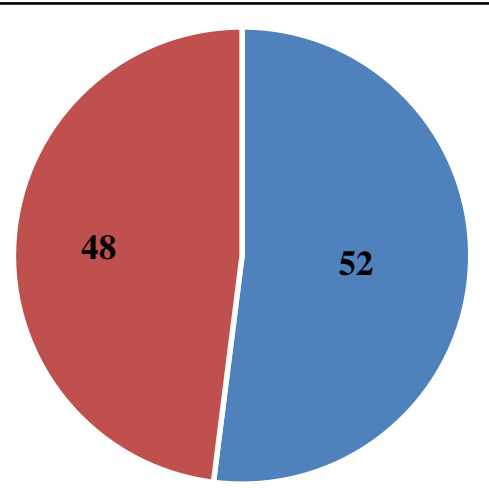

- Single drug $\quad$ - Multiple drug

Figure 1: Classification as per type of drug combination $(n=100)$.

Table 1: Fulfilment of WHO criteria by DPLs $(n=100)$.

\begin{tabular}{|lll|}
\hline Parameter & Yes $(\%)$ & No $(\%)$ \\
\hline Generic name & 100 & 0 \\
\hline Brand name & 100 & 0 \\
\hline Content/active ingredient & 100 & 0 \\
\hline Problem causing ingredient & 0 & 100 \\
\hline Approved use & 100 & 0 \\
\hline Dosage form & 100 & 0 \\
\hline Adverse reactions & 45 & 55 \\
\hline Contraindications & 39 & 61 \\
\hline Interactions & 39 & 61 \\
\hline Manufacturer details & 67 & 33 \\
\hline References & 80 & 20 \\
\hline Complete & 0 & 100 \\
\hline
\end{tabular}


References were mentioned in $80 \%$ of literatures. Total number of references were 207, out of which $174(84 \%)$ were from journal articles, $1 \%$ from websites and $15 \%$ from other sources. Among the journal article references $101(58 \%)$ were after 2010 and $73(42 \%)$ were before 2010. Out of all the articles mentioned $133(76 \%)$ were from indexed journals and $41(26 \%)$ were from nonindexed journals. $100(57 \%)$ were research articles and 74 $(43 \%)$ were review articles or others (Table 2).

Table 2: Classification of references as per its source $(n=207)$.

\begin{tabular}{|c|c|c|c|}
\hline Sr. no. & References & Number & Percentage \\
\hline 1. & $\begin{array}{l}\text { Total number of } \\
\text { references cited }\end{array}$ & 207 & $100 \%$ \\
\hline 2. & $\begin{array}{l}\text { Journal article } \\
\text { reference, } \\
\text { categorised by } \\
\text { publication date }\end{array}$ & 174 & $84 \%$ \\
\hline$\bullet$ & After 2010 & 101 & $58 \%$ \\
\hline$\bullet$ & Before 2010 & 73 & $42 \%$ \\
\hline$\bullet$ & Research article & 100 & $57 \%$ \\
\hline$\bullet$ & $\begin{array}{l}\text { Review article or } \\
\text { others }\end{array}$ & 74 & $43 \%$ \\
\hline$\bullet$ & Indexed journals & 133 & $76 \%$ \\
\hline$\bullet$ & $\begin{array}{l}\text { Non-indexed } \\
\text { journals }\end{array}$ & 41 & $26 \%$ \\
\hline 3. & Website & 2 & $1 \%$ \\
\hline 4. & Textbook & 0 & $0 \%$ \\
\hline 5. & Other Sources & 31 & $15 \%$ \\
\hline
\end{tabular}

The ratio of font size of brand versus generic drugs was also analysed and it was found that the ratio was less than 3 times of the generic drugs in only $10 \%$ of the cases, 3-6 times bigger in $75 \%$ of the cases and $>6$ in $5 \%$ of the cases. The font size of the references was also analysed and it was found that $32 \%$ belonged to size $8,44 \%$ were of size 9 and $24 \%$ were of size 10 . Images were also analysed for their relevance and it was found that images were present in $57 \%$ of the cases out of which only $33 \%$ of the images were related to the drug mentioned.

\section{DISCUSSION}

Every year, lots of new drugs enter the Indian market. Many of them are "me too" products, not genuine innovations. They join more than 20,000 drug formulations already in the market. ${ }^{1}$ Printed promotional literature is easily available and an important source of information. The information provided for drug promotion greatly influences the prescribing pattern of physicians and should be accurate, scientific and evidence based to keep the doctors informed about the company's products and all related information. ${ }^{8}$ This study was taken up to critically review the DPL's and to assess the collected DPLs for completeness and validity of the information presented in it, using World Health Organization (WHO) criteria for ethical medicinal drug promotion.
None of the DPL's fulfilled all the criteria expected by the WHO which was in concurrence with many other studies. ${ }^{1-}$ ${ }^{3}$ Out of all the drug promotional literatures half were single drug and the other half were multidrug combinations as seen in other studies. ${ }^{2}$ In this study, it was found that generic name, brand name, active ingredient, approved use and dosage form were mentioned in $100 \%$ of the drug promotional literatures and this finding was similar to other studies. ${ }^{2,8}$ Problem causing ingredient was not mentioned in any of the cases which was also a lacunae observed in several other studies. ${ }^{2,4}$

Safety information is of critical importance for a physician while prescribing a drug but important safety information was neglected in many of the DPL's. Adverse drug reactions were mentioned in only half of the cases, contraindications as well as drug interactions were mentioned in few of the DPL's. These findings were similar to other studies. ${ }^{8,9}$ Manufacturers details were mentioned in $67 \%$ of the cases which was similar to the findings seen in the study conducted by Sonwane et al. ${ }^{1}$

References were mentioned in $80 \%$ of literatures which was similar to several other studies and it was also observed that the size of a significant number of references was very less in comparison to the brand name of the drug. ${ }^{1,8,10}$ Total number of references were 207, out of which majority $(84 \%)$ were from journal articles similar to other studies conducted. ${ }^{1,2,8,11}$ Among the journal article references 101 (58\%) were after 2010 and 73 (42\%) were before 2010. A significant number of articles were from before 2010 and it shows that drug manufacturers are peddling old claims as it is highly unlikely that no new data has been published since then. Majority of the articles cited were research articles (57\%) and the remaining were review articles which was similar to another study conducted. ${ }^{2}$ References added from review article may not give complete information.

Inclusion in a better indexed database is the marker of the journal's merit and holds more credibility. Hence, any claim taken from an indexed journal is more authenticated than a non-indexed journal. ${ }^{12}$ In this study it was noted that a large majority $(76 \%)$ of the articles were from indexed journals which is encouraging. All the brochures attractive and appealing to look at and many contained images. Images if used correctly can create the appropriate impact but it was observed that only $33 \%$ of the images used were of any relevance to the drug or its uses which were findings similar to other studies. ${ }^{4,13}$

Even though WHO has not issued any guidelines regarding the font size of generic name vs brand name, we analysed this ratio and it was observed that the brand name was 3-6 times bigger compared to the generic name of the drug in majority of the DPL's which indicates that pharmaceutical companies are trying to draw the attention of the physicians towards the brand name over the generic name. This finding was not observed in any other study and still has to be substantiated. 
This study has several limitations, firstly the relatively small sample size. Secondly, the study was conducted only in a single centre. Multicentric studies with a larger sample size will yield better results. Lastly, out of all the promotional material only DPL's were analysed. Other promotional materials were not analysed and if done so will give deeper knowledge regarding the drug promotional activities. Further studies are required to assess the knowledge, awareness and practices of the physicians while evaluating DPL's to ensure ethical drug promotional activities and rational prescription.

Physicians keep abreast with the latest development in the drugs and pharmacotherapeutics through the information disseminated by the pharmaceutical companies. There are many code of practices developed for ideal drug promotion but the drawback is that they are not always followed by the pharmaceutical companies and they have been vulnerable to criticism for some of their marketing practices. ${ }^{14}$ The direct to physician type of marketing may influence the prescribing pattern of the physicians with no benefit to the patient and also lead to irrational prescribing practices. Excessive emphasis on the benefits with inadequate/no information on the risks may lead to a false sense of security among the prescribers. ${ }^{15}$ Hence, development of laws and their implementation by drug manufacturers, practitioners' awareness and strengthening of existing guidelines can be beneficial measures in this issue. The combined efforts of the pharmaceutical companies, regulators and prescribing physicians which lead to better and more rational drug prescription.

\section{CONCLUSION}

None of the DPL's satisfied all the criteria laid down by the WHO. The pharmaceutical companies should comply with the guidelines more meticulously. Incomplete information may lead to irrational prescription of drugs. Therefore, stricter regulations need to be implemented by the concerned authorities for promotional activities and physicians must also carefully evaluate DPL's before considering the same for prescribing.

Funding: No funding sources

Conflict of interest: None declared

Ethical approval: The study was approved by the Institutional Ethics Committee

\section{REFERENCES}

1. Sonwane PG, Karve AV. IJBCP Drug promotional literature: Does pharmaceutical industry follow WHO guidelines? Int J Basic Clin Pharmacol. 2017;6(7):17903.

2. Jadav SS, Dumatar CB, Dikshit RK. Drug promotional literatures (DPLs) evaluation as per World Health Organization (WHO) criteria. J Appl Pharmaceu Scien. 2014 Jun 1;4(6):84.
3. Randhawa G, Singh N, Rai J, Kaur G, Kashyap R. A Critical Analysis of Claims and Their Authenticity in Indian Drug Promotional Advertisements. Advances in Medicine. 2015;2015:1-7.

4. Ganashree P, Bhuvana K, Sarala N. Critical review of drug promotional literature using the World Health Organization guidelines. J Res Pharm Pract [Internet]. 2016;5(3):162-5. Available at: http://www.ncbi.nlm.nih.gov/pubmed/27512705. (Cited 2019 Feb 18).

5. Shubha R, Taj S, Bindumathi PL. A cross sectional study of drug promotional literatures in a tertiary care hospital. Int J Basic Clin Pharmacol. 2017;6(1):137-40.

6. Stryer D, Bero LA. Characteristics of materials distributed by drug companies. Journal of General Internal Medicine. 1996;11(10):575-83. Available at: http://www.ncbi.nlm.nih.gov/pubmed/8945688

7. Ethical criteria for medicinal drug promotion [Internet]. (Cited 2019 Feb 19). Available at: http://apps.who.int/medicinedocs/documents/whozip08e /whozip08e.pdf

8. Jadav SS, Dumatar CB, Dikshit RK. Drug promotional literatures (DPLs) evaluation as per World Health Organization (WHO) criteria. J App Pharmace Scien. 2014 Jun 1;4(6):84.

9. Sharmin R, Sharmin ZR, Mosaddek ASM, Islam MZ, Rahman MF, Parvin R, et al. Medicine promotional literature as a source of updated information in Bangladesh: Do those advertising literature promote continued medical education or deceptive advertising? Acta Medi Int. 2017;4(2):20. Available at: http://www.actamedicainternational.com/text.asp?2017/ 4/2/20/220215

10. Jain V, Kaore S, Amane H, Jain M, Katakwar M, Thawani V. Evaluation of rationality of printed promotional medicine literature. Int J Heal Alli Scienc. 2016;5(1):45. Available at: http://www.ijhas.in/text.asp?2016/5/1/45/173871

11. Gautam SR, Chugh PK, Sah RK, Tripathi CD. Critical appraisal of drug promotional literature using World Health Organisation guidelines. Int $\mathrm{J}$ Basic Clin Pharmacol. 2017;6(8):2014.

12. Natarajan $\mathbf{S}$. The relevance of indexed journals. Ind $\mathbf{J}$ Ophthalmol. 2016;64(5):331.

13. Khakhkhar T, Mehta M, Shah R, Sharma D. Evaluation of drug promotional literatures using WHO guidelines. Journal of Pharmaceutical Negative Results. 2013 Jan $1 ; 4(1): 33$.

14. Parli K, Reema R, Devang R, Supriya M. Evaluation of promotional drug literature provided by medical representative at a tertiary care hospital. Interactions. 2017 Apr 1;34(160):17-5.

15. Hoovinahole S, Kamath A. A study of adherence of drug promotional literatures from various clinical specialties to the World Health Organization ethical criteria for drug promotion. J Pharm Negat Results [Internet]. 2016;7(1):37. (Cited 2019 Apr 1).

Cite this article as: Vyas N, Shahani S. Analysis of drug promotional literatures in a tertiary care hospital: a cross sectional study. Int J Basic Clin Pharmacol 2019;8:1102-5. 